\title{
4
}

\section{Wind Turbine Modelling of a Fully-Fed Induction Machine}

\author{
Umashankar S, Dr. Kothari D P and Mangayarkarasi P \\ VIT University \& Anna University \\ Tamilnadu, \\ India
}

\section{Introduction}

This document provides detail about modelling Fully-Fed Induction Generator (FFIG) based wind farm. The generator torque model was specified either as a constant derived from nominal turbine power or pitch control block depends on the wind speed.

This model has been simulated under the normal operating condition and three different fault conditions. The performance of the model analysed based on the speed, torque, voltage, current, and power of generator, converter and grid.

This document contains the model design parameters and simulation results.

\section{Wind farm model}

The model in Fig.1. is the top level model of the fully-fed induction generator based wind farm with the following subsystems:

1. Induction generator and its torque subsystem

2. Converter Bridges

3. Machine bridge control

4. Network bridge control

5. Pitch Controller

6. Transmission line and grid

\subsection{Induction generator}

The Induction Generator block is a standard block in the SimPowerSystems Application Library, Machines. Its design is based on reference 3

\subsection{Converter bridges}

This is a standard block in SimPowerSystems, Power Electronics, Universal Bridge. The pulses for these two bridges given from subsystems MCB control and NWB control, which are modelled based on the vector control principles. Its design parameters are based on reference 12 .

Source: Wind Power, Book edited by: S. M. Muyeen,

ISBN 978-953-7619-81-7, pp. 558, June 2010, INTECH, Croatia, downloaded from SCIYO.COM 


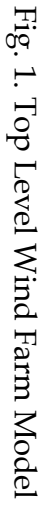
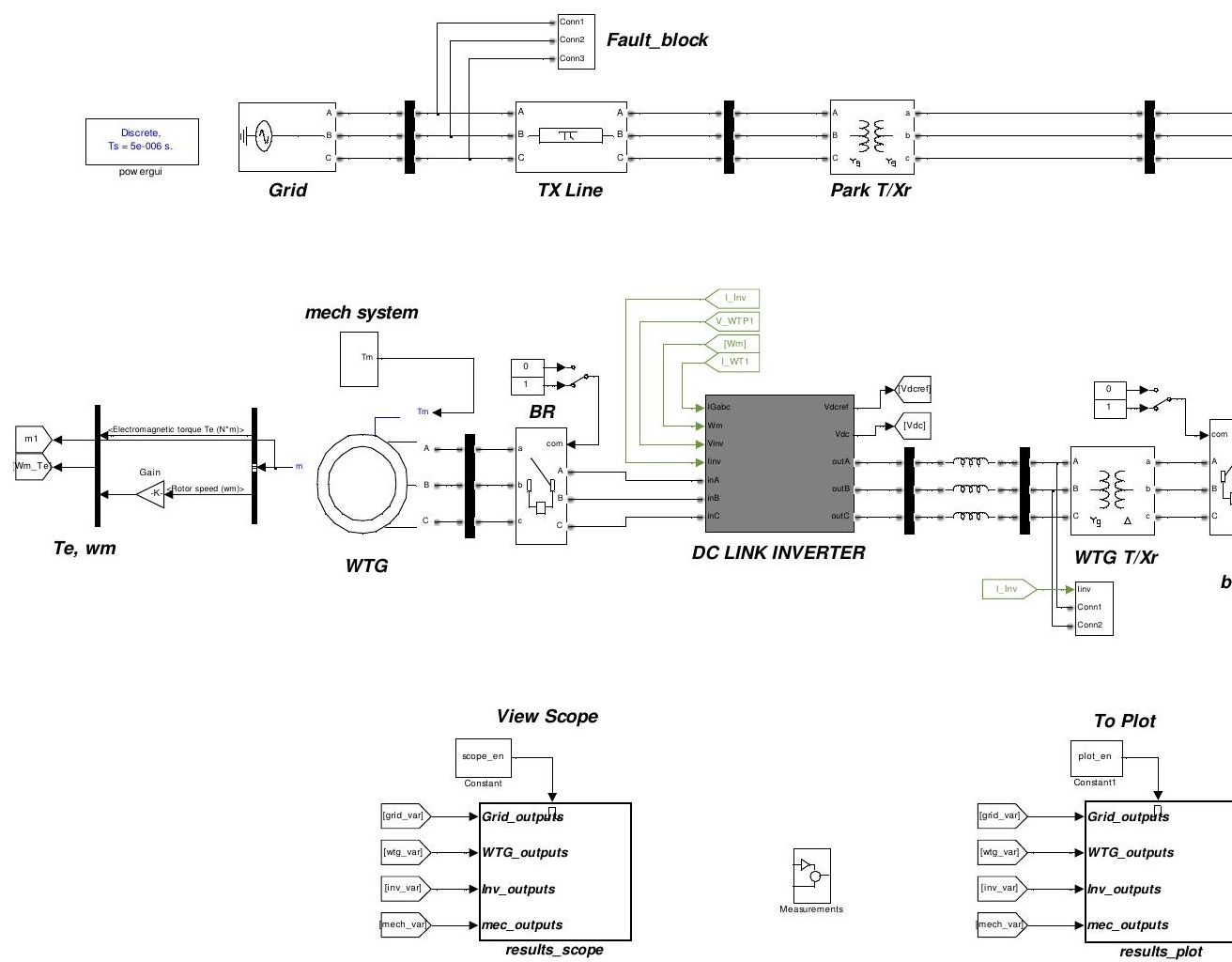


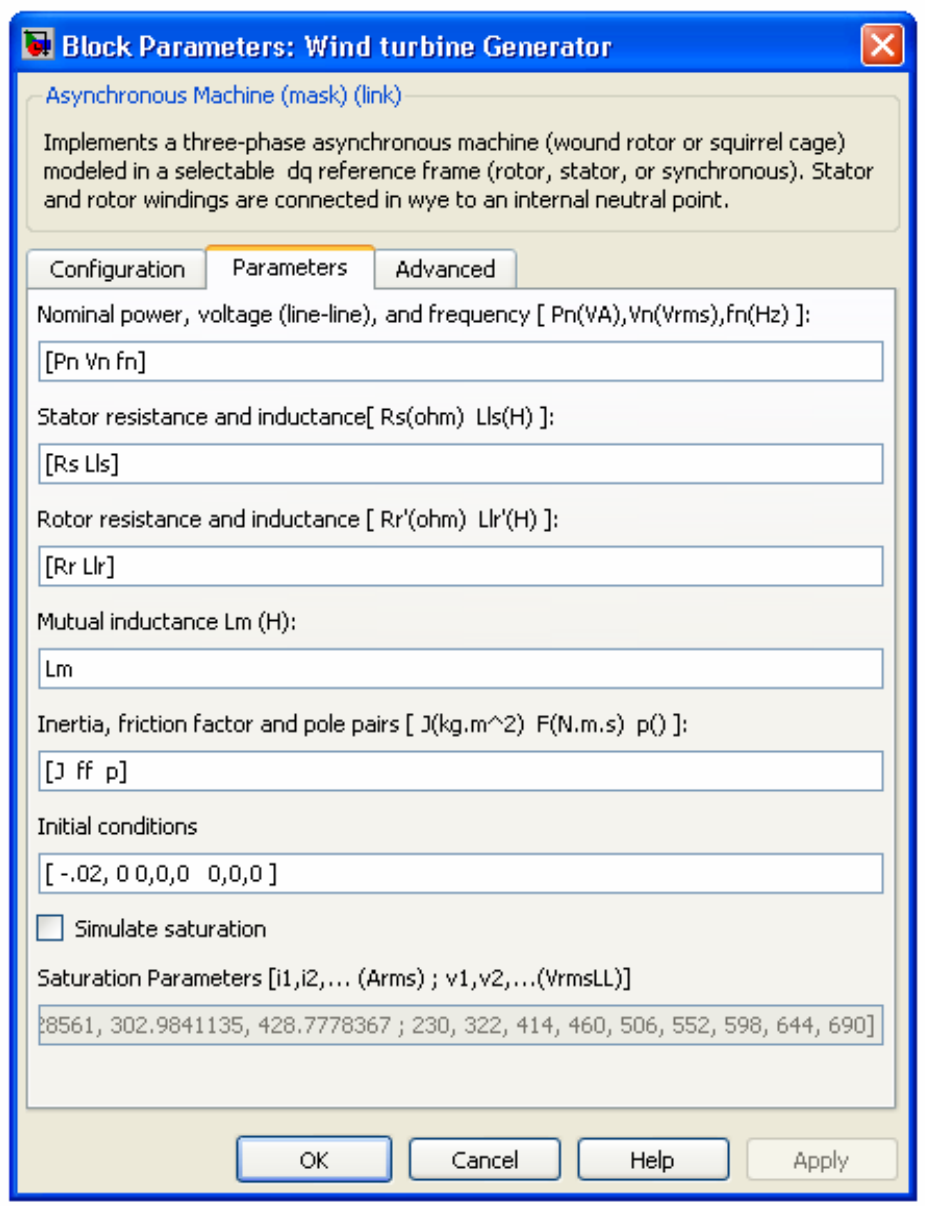

Fig. 2. Wind Turbine Generator mask dialogue

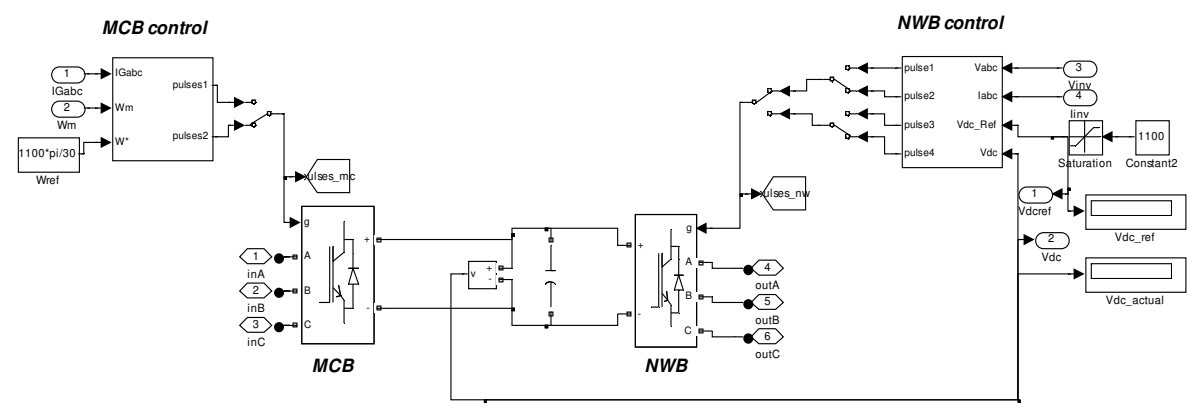

Fig. 3. DC link-Inverter with control blocks 


\subsection{Machine-bridge}

This subsystem was modelled based on the vector control principles, in which the flux and torque controlled with the use of speed controller and hysteresis current controller. All the parameters are converted into two phase quantities and then the required flux and torque are calculated using abc to dq conversion. Here one provision is also available for checking the controller response for step change in speed.

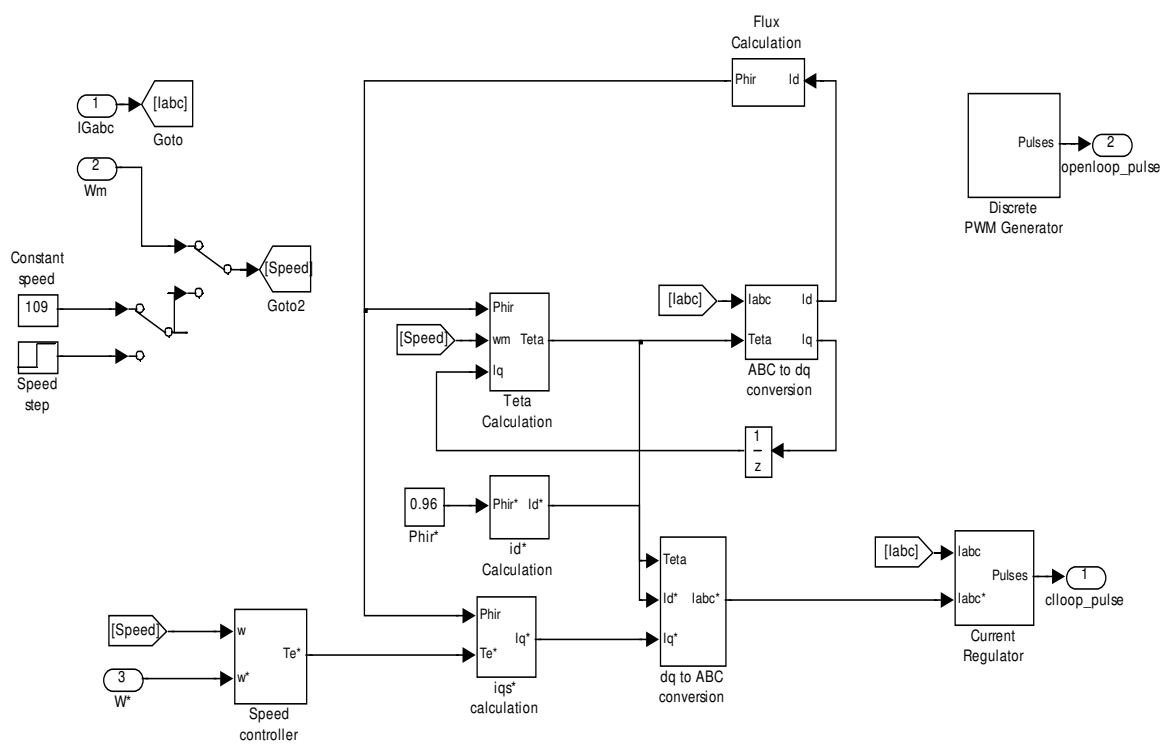

Fig. 4. Machine bridge control block

\section{4 network-bridge}

This subsystem was modelled based on the independent real and reactive power control using voltage and current controller. All the AC quantities are converted into two phase dqo and then the voltage and current references are estimated. Here one more provision is also available to give different type of pwm pulses, open loop as well as closed loop.

\subsection{Transmission line and grid specifications}

The transmission line is modelled as simple $\Pi$ equivalent circuit block which is available with the standard block in SimPowerSystems, Elements. Its design parameters are specified in reference 8 .

The Grid block is a standard block in the SimPowerSystems, Electrical Sources. Its design parameters are based on reference 8 . The grid condition is based on the parameters under short-circuit section either by providing short-circuit power SCVA, Base Voltage Vrms, X/R ratio SCR or by Source Resistance Rs and inductance Ls. 


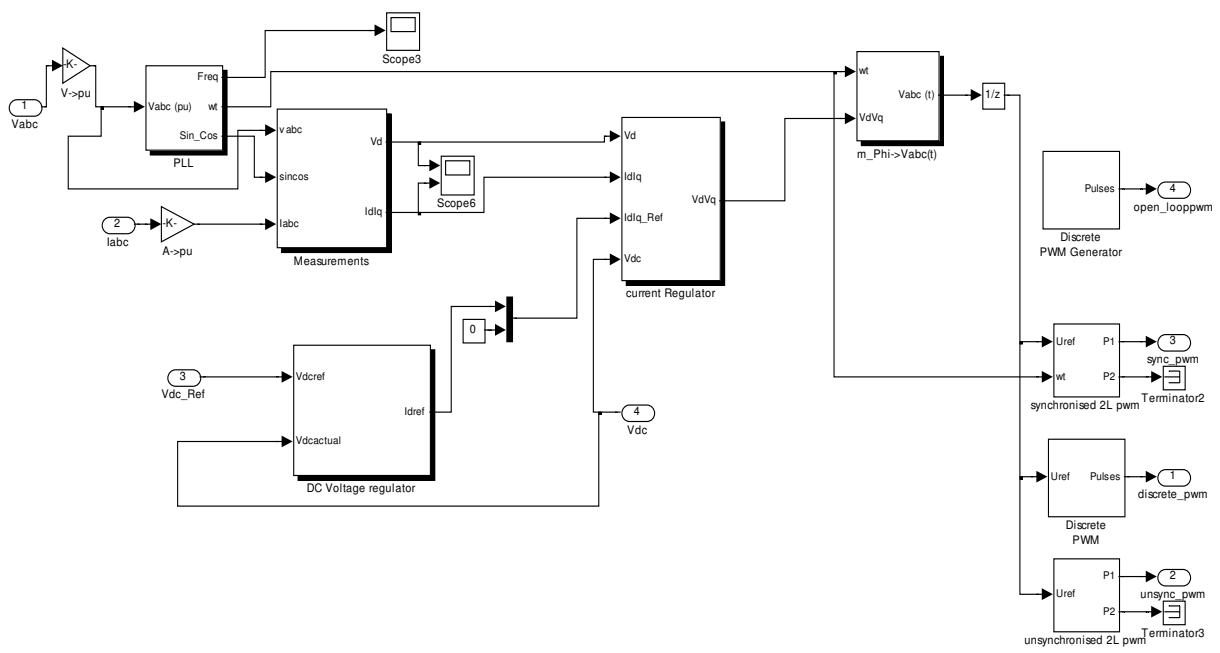

Fig. 5. Network bridge control block

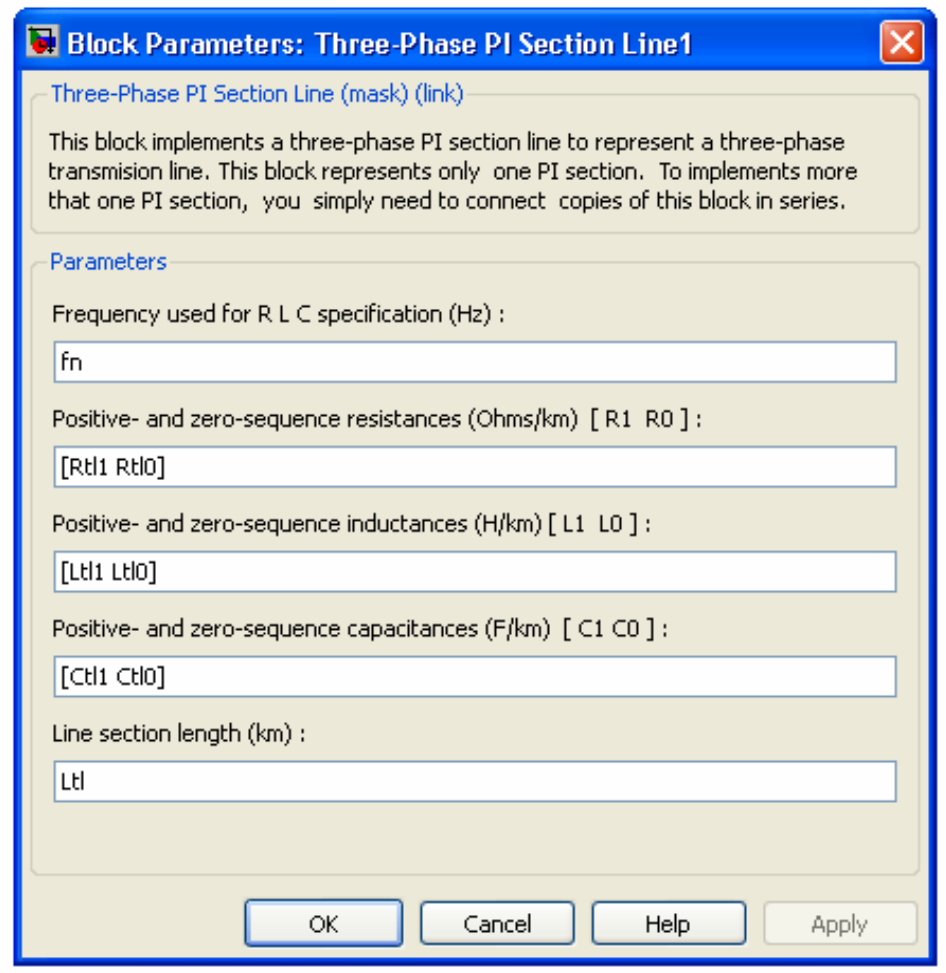

Fig. 6. Transmission Line П equivalent mask dialogue 


\subsection{Pitch controller}

The pitch controller block is a standard SimPowerSystems Pitch Controller Library block. We have made some modifications to enable or disable the controller based on the wind speed. Also the existing standard wind turbine block will give the per unit torque value. Then this is converted into actual value by manually adding the gain block which multiplies it with the base torque.

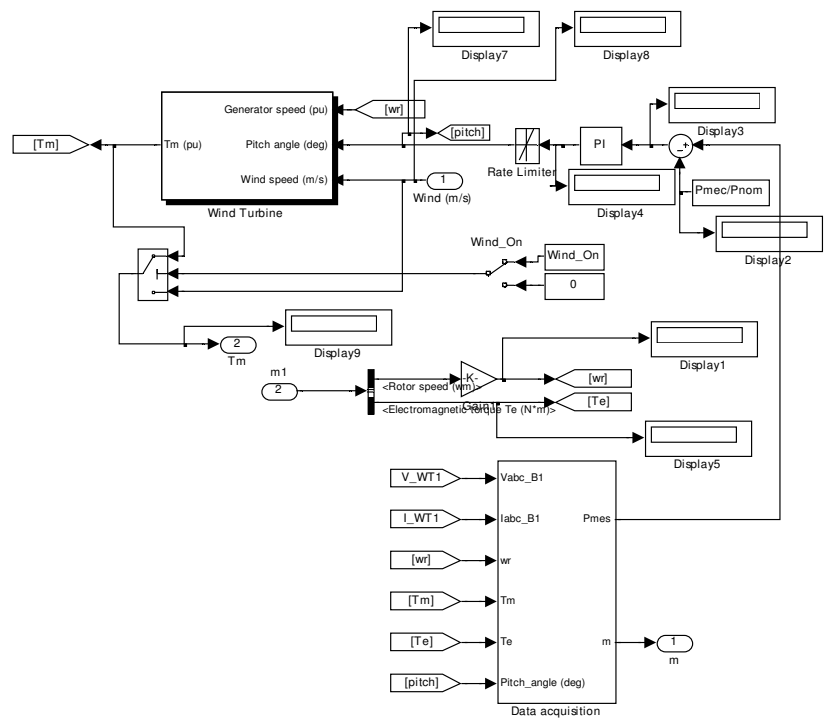

Fig. 7. Pitch controller block

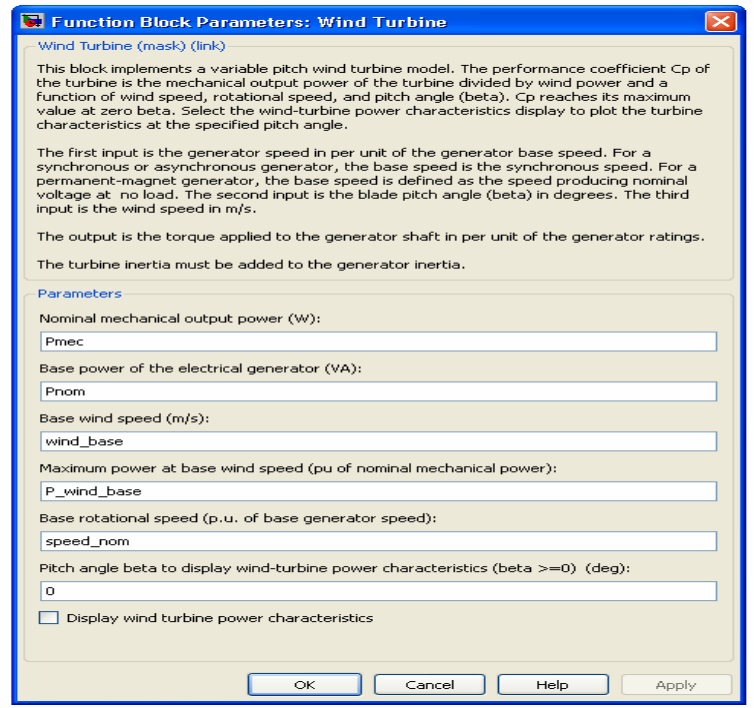

Fig. 8. Wind Turbine mask dialogue 


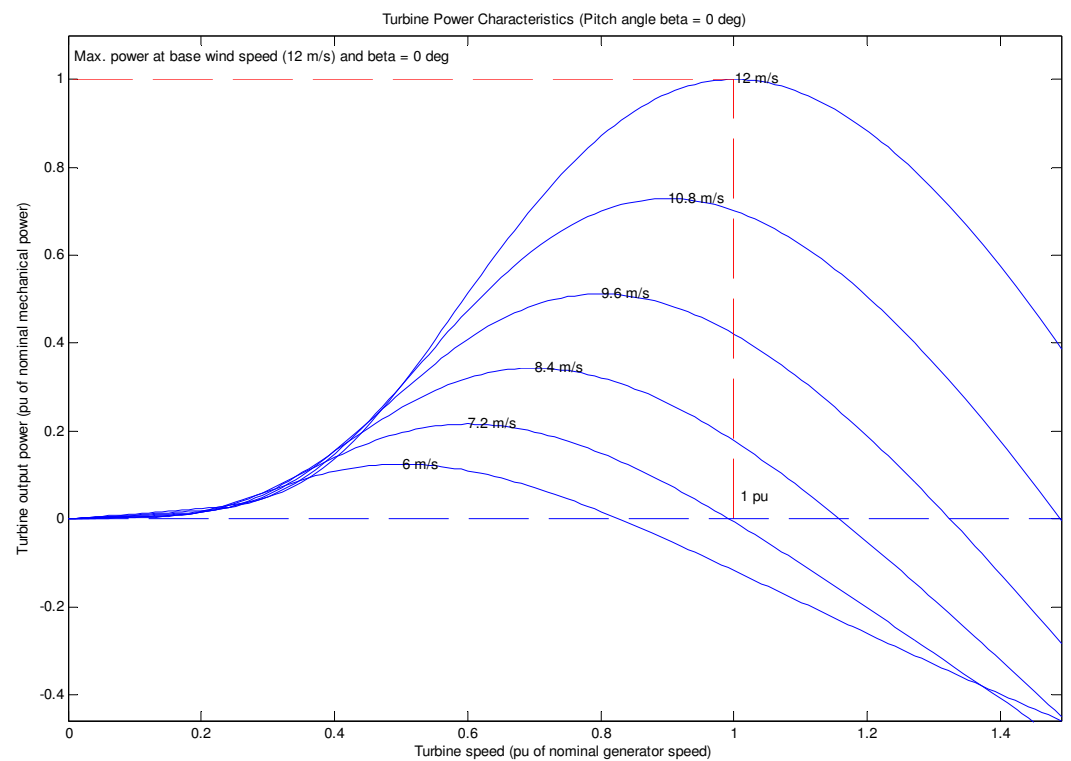

Fig. 9. Wind Turbine characteristic curves

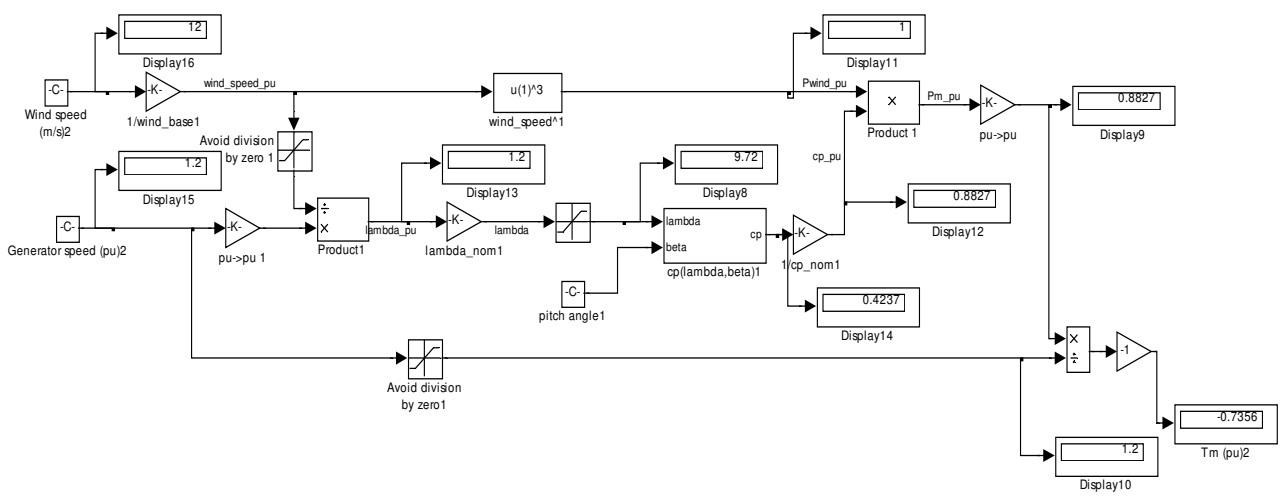

Run the M-file Turbine_model_initialisation.m first to assign values to Parameters

Fig. 10. Wind Turbine Block

\section{Modelling notes and assumptions}

The model is completely discrete; there are no continuous states.

The model is full parameterised; it has no hard coded parameter values.

All the model parameter values are set up in the initialisation file. The model could be used for a different wind turbine simply by changing the initialisation file; no change to the model is needed. 
The stiffness of the shaft between the generator and wind turbine was chosen so that mechanical resonance occurred at $5 \mathrm{~Hz}$. This was done to demonstrate the effectiveness of active damping.

MATLAB mechanical dynamic model has been made discrete. The sample time chosen for the discrete model, 5X10-6 s, gave time domain results very close to the continuous model for $5 \mathrm{~Hz}$ resonant frequency.

The model assumes that the converter DC link voltage is maintained constant during the simulations, thus the energy storage of the DC link due to the DC link capacitor has not been modeled.

The standard MATLAB wind turbine model has been used, which is analytic but doesn't completely agree with the data provided by client in reference 1 .

The wind speed is assumed to be rated value and hence the torque and speed of the generator.

The wind turbine is considered to be delivering the power to grid and not to local loads.

All the initial conditions are assumed to be zero, unless otherwise specified externally and losses neglected to make the model simple and calculation easier.

As the objective of the modelling work was to get the correct transient response during a grid fault, generator and converter losses neglected or assumed to be zero.

The model is not analysed under Grid Fault Ride through Conditions, also not able to maintain the stability due to unavailable provision for voltage stabilization.

\section{Results}

Simulation results are provided for the following different cases

1. Normal operation

2. Grid Fault Analysis

a. Three-Phase Line to Ground Fault

b. Two-Phase Line to Line Fault

The following category figures are plotted for each scenario

1. Generator Voltage, Current, Real Power and Reactive Power

2. Generator Electromagnetic Torque, Speed

3. Mechanical Torque, Rotor and Wind Speed, Pitch

4. Inverter Voltage, current, PWM pulses, Vdc

5. Grid Voltage, Current, Real Power and Reactive Power

\subsection{Normal operation}

To analyse the model under normal operating condition, follow the steps in the below snapshot of the matlab command window. After the simulation, command window will prompt for user input to display the results and to save the figures. To start with run the main.m file in command window and follow the steps below:

\subsubsection{Comments on the result}

At rated torque and speed, the FFIG delivers the rated power to grid under normal operation. The negative sign in the generator power waveform denotes consumption and positive sign denotes generation of power. Thus the generator delivering rated power to grid by absorbing some reactive power. 


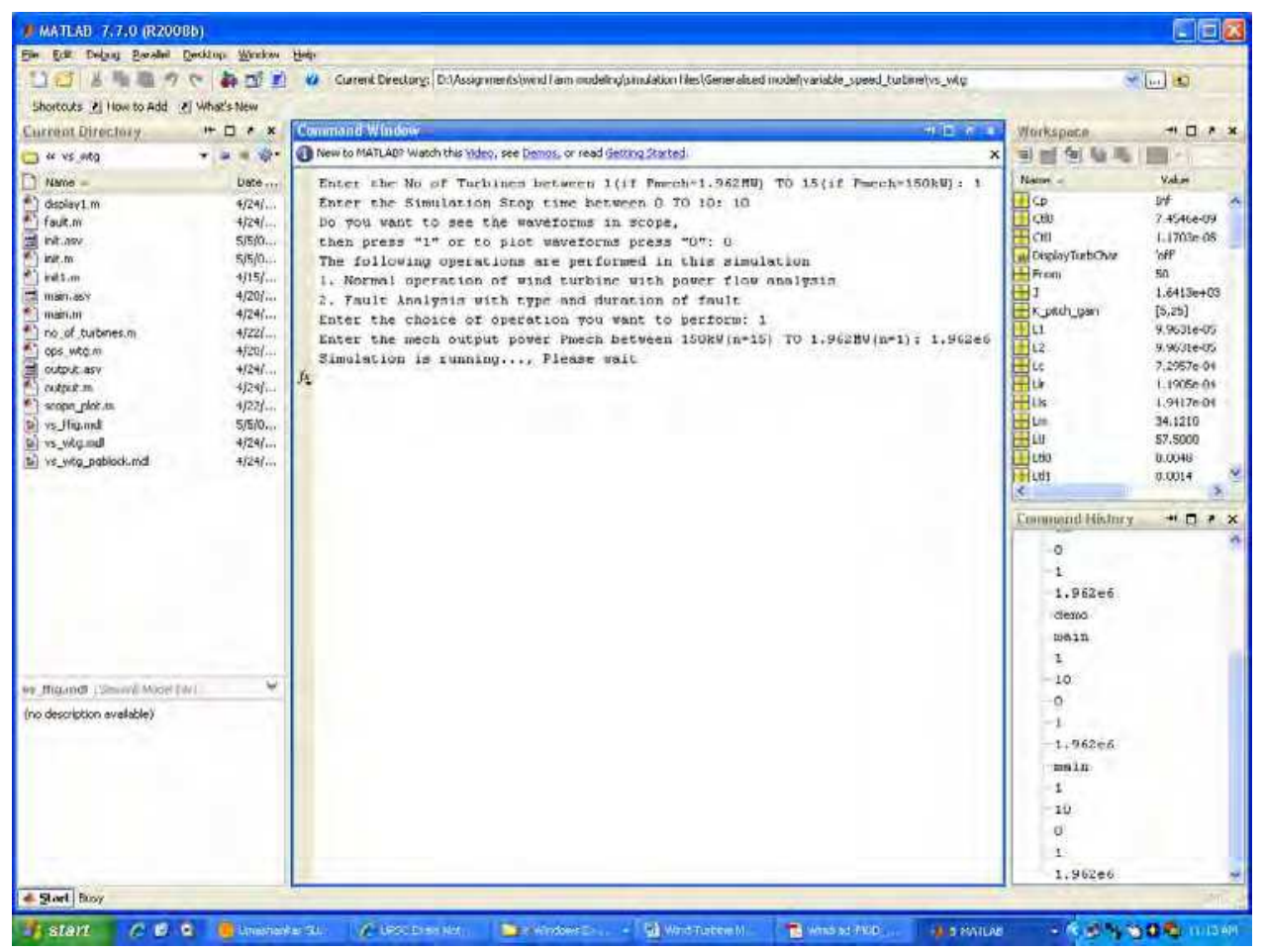

Fig. 11. Matlab command window as user interface, normal operation
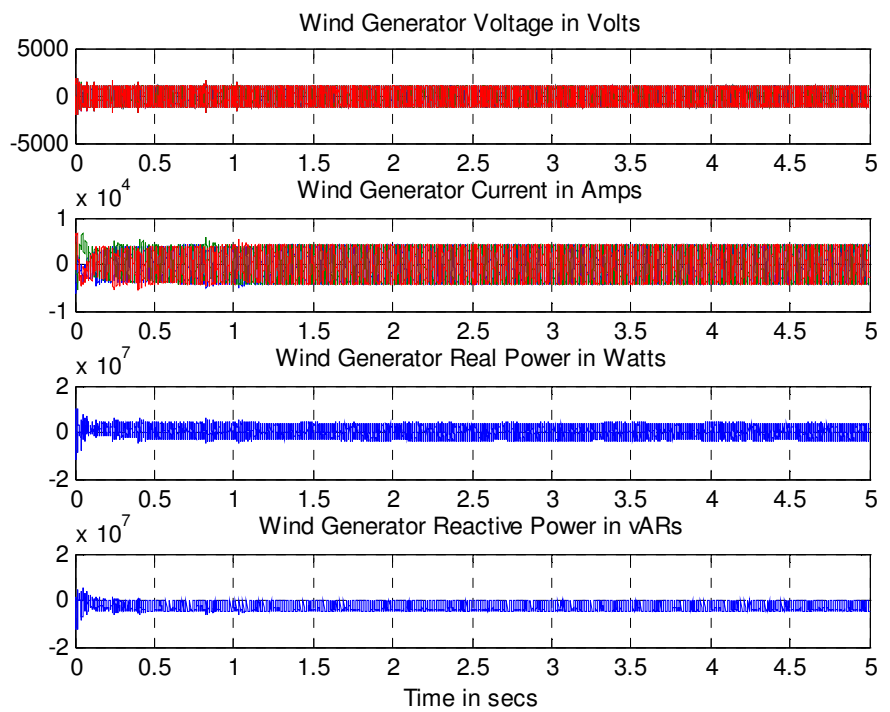

Fig. 12. Generator-side electrical outputs, normal operation 

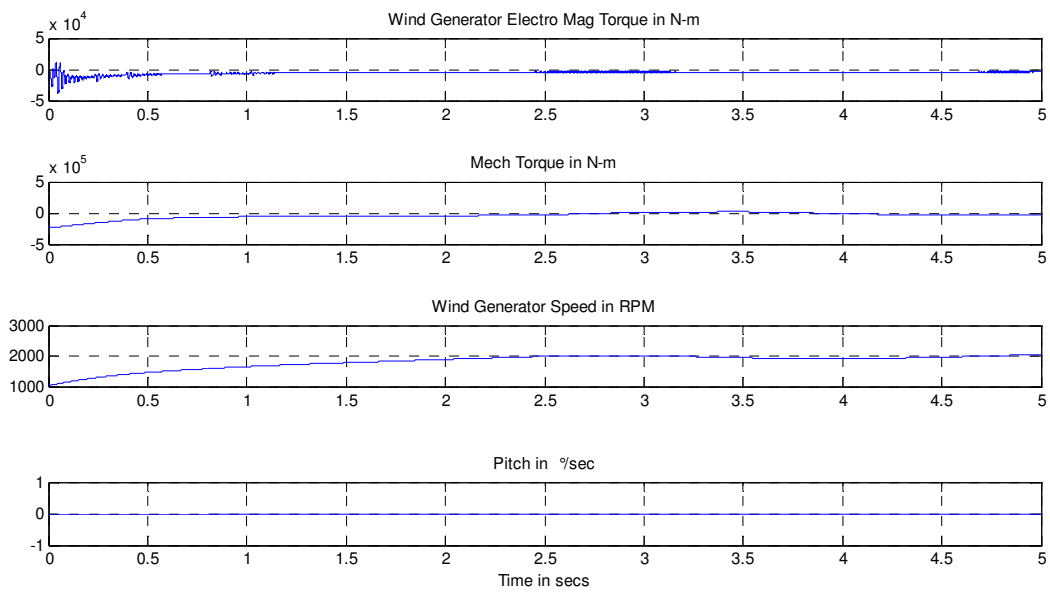

Fig. 13. Generator-side mechanical outputs, normal operation
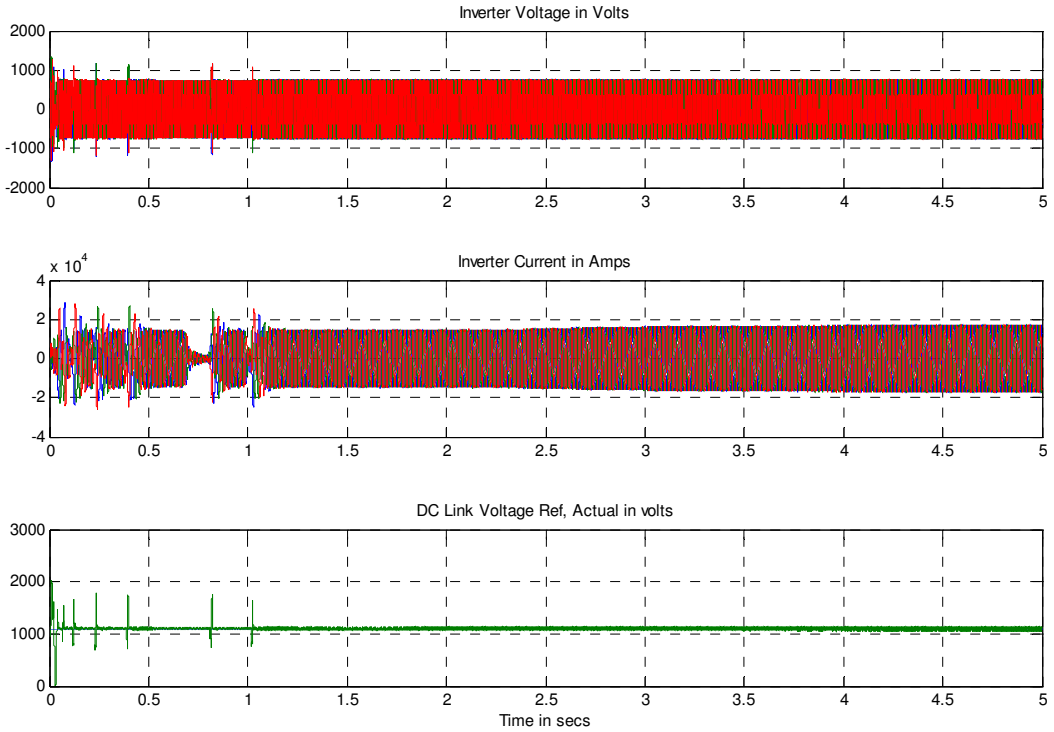

Fig. 14. Inverter Electrical outputs, normal operation 

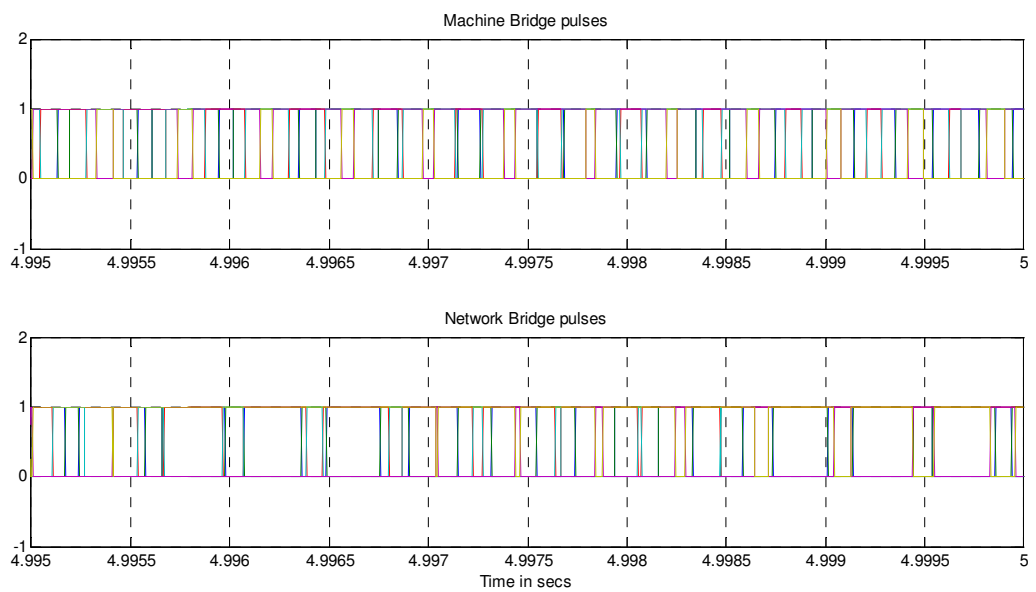

Fig. 15. PWM pulse outputs, normal operation
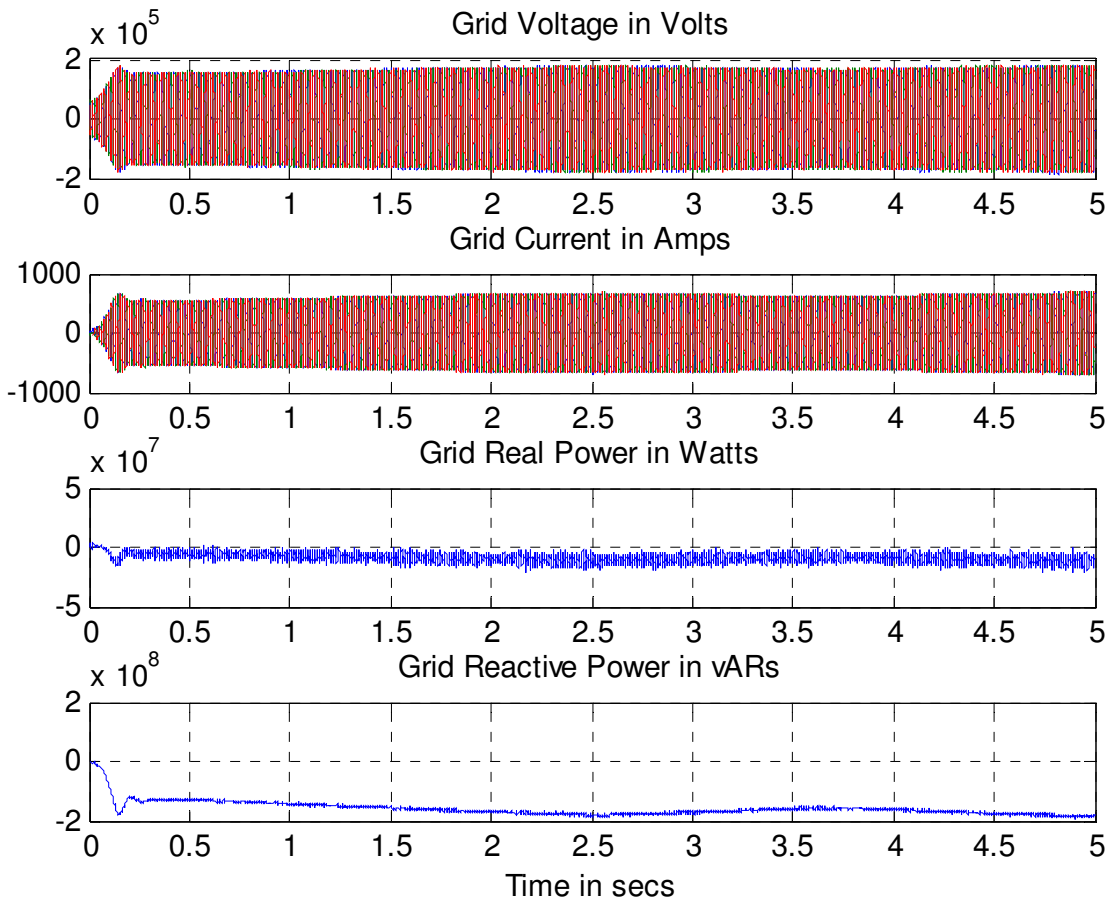

Fig. 16. Grid-side Electrical outputs, normal operation 
The negative sign in torque denotes it as generating torque. The real power is delivered to grid with some loss of power in the transformer, cable and transmission line.

Fig.14. shows inverter output settles after one sec, before that there are some spikes occurring at regular intervals. This can be avoided by providing $\mathrm{dv} / \mathrm{dt}$ filters in the output. The dc regulator maintains the dc voltage at its constant level as seen from fig.14.

The PWM pulse output shown in fig.15. for both machine and network bridges. The modulation is unsynchronised sine pwm and it's based on the closed loop bridge control.

\subsection{Three-phase to ground grid fault}

To analyse the model under three-phase to ground grid fault condition, follow the steps in the below snapshot of the matlab command window. After the simulation, command window will prompt for user input to display the results and to save the figures. To start with run the main.m file in command window and follow the steps below:

\subsubsection{Comments on the result}

At rated torque and speed, the FFIG delivers the rated power to grid under normal operation. At time $t=2.5 \mathrm{~s}$, three-phase to ground fault is created at the grid side transmission line hence the grid current abruptly increased. The generator voltage, current will not become zero as like in fixed speed wind turbine and speed will increase above rated speed. Also the actual dc voltage becomes zero with that of reference.

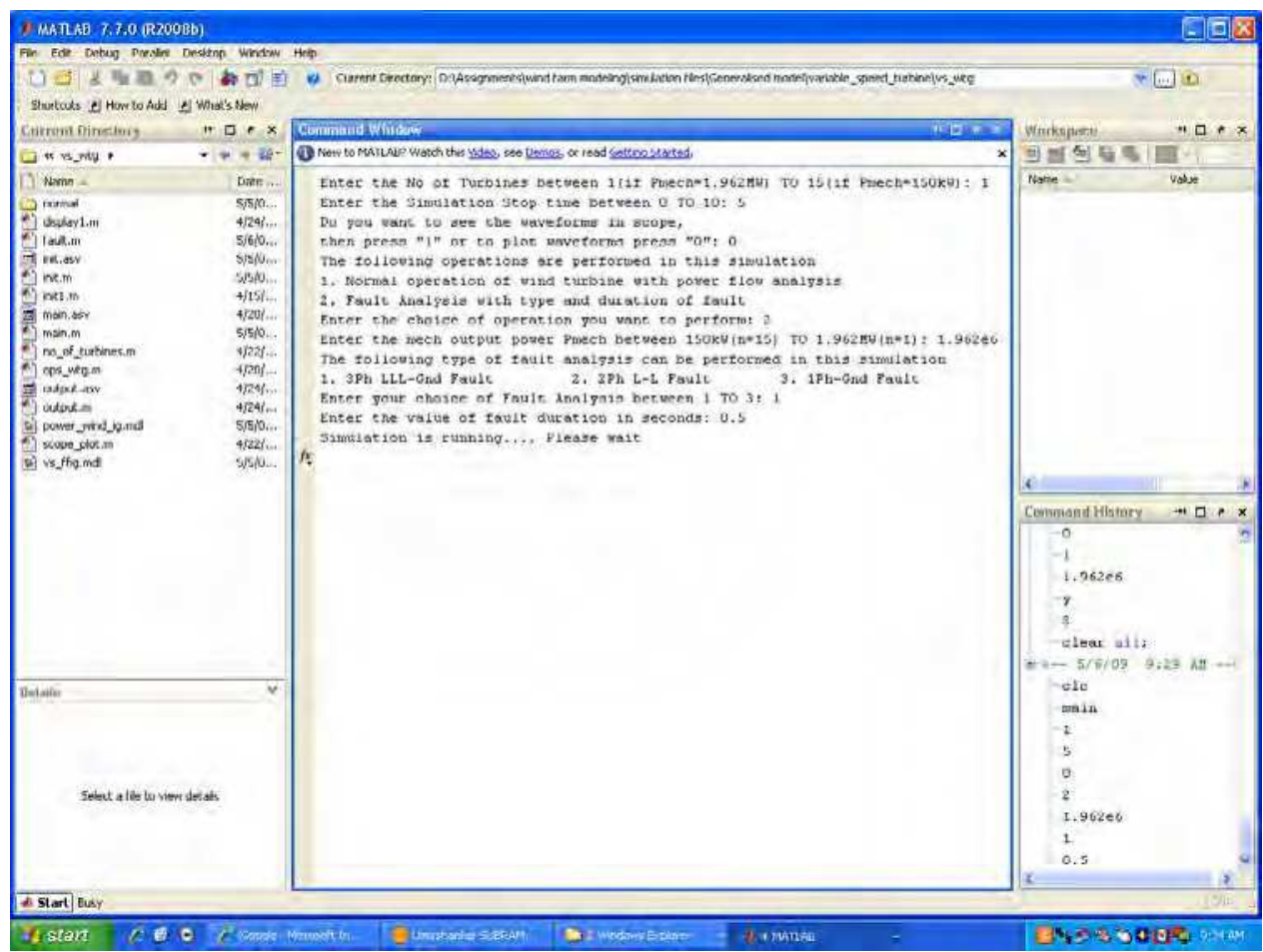

Fig. 17. Matlab command window as user interface, 3 phase grid fault 

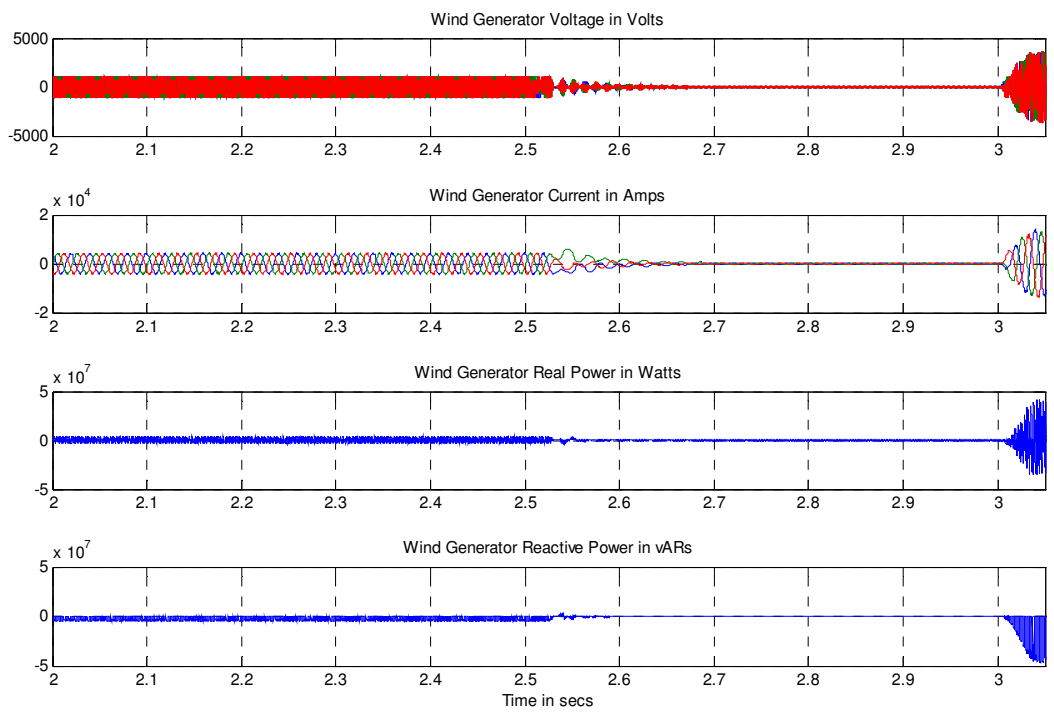

Fig. 18. Generator-side electrical outputs, 3phase grid fault
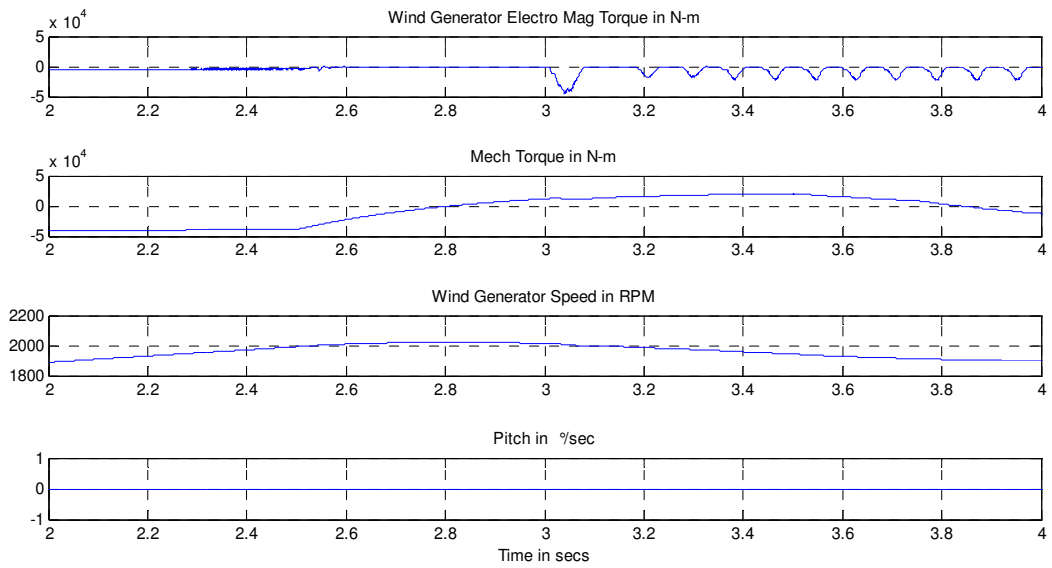

Fig. 19. Generator-side mechanical outputs, 3phase grid fault 
It is evident from the fig.19. that there is a mechanical torque reversal during the grid fault and there are some oscillations in all the waveforms after the fault has been cleared. But the shaft between generator and wind turbine will ring at its natural frequency.

At time $t=3 \mathrm{~s}$ fault is cleared and all the quantities will slowly come to its previous condition of normal operation. Since electromagnetic torque becomes discontinuous during grid fault and initial conditions are changed after fault removal, it will take more time to settle in steady state. Implementation of GFRT will rectify this issue and stabilize the electrical parameters during fault and after fault removal.
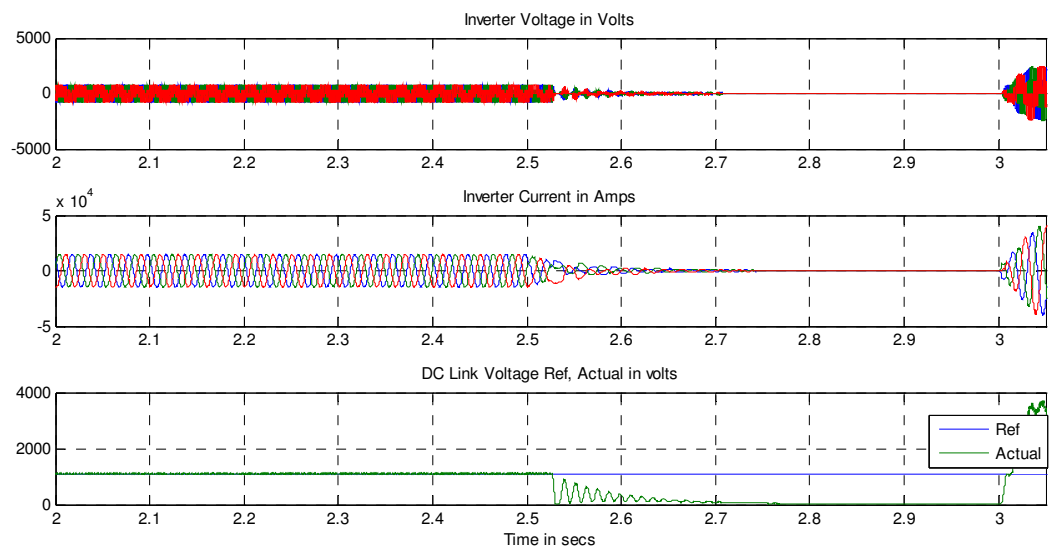

Fig. 20. Inverter Electrical outputs, 3phase grid fault
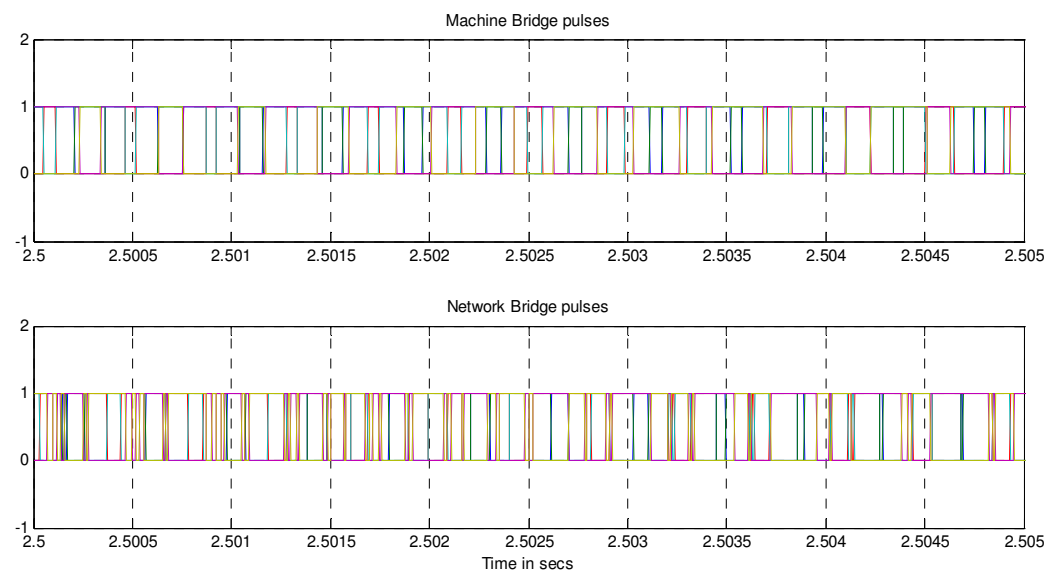

Fig. 21. PWM pulse outputs, 3phase grid fault 

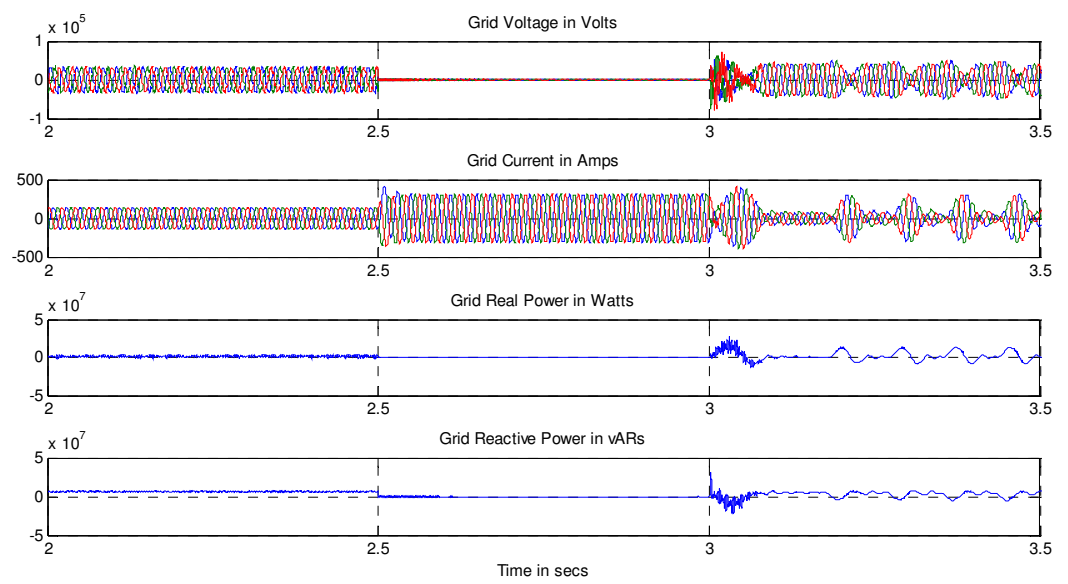

Fig. 22. Grid-side Electrical outputs, 3phase grid fault

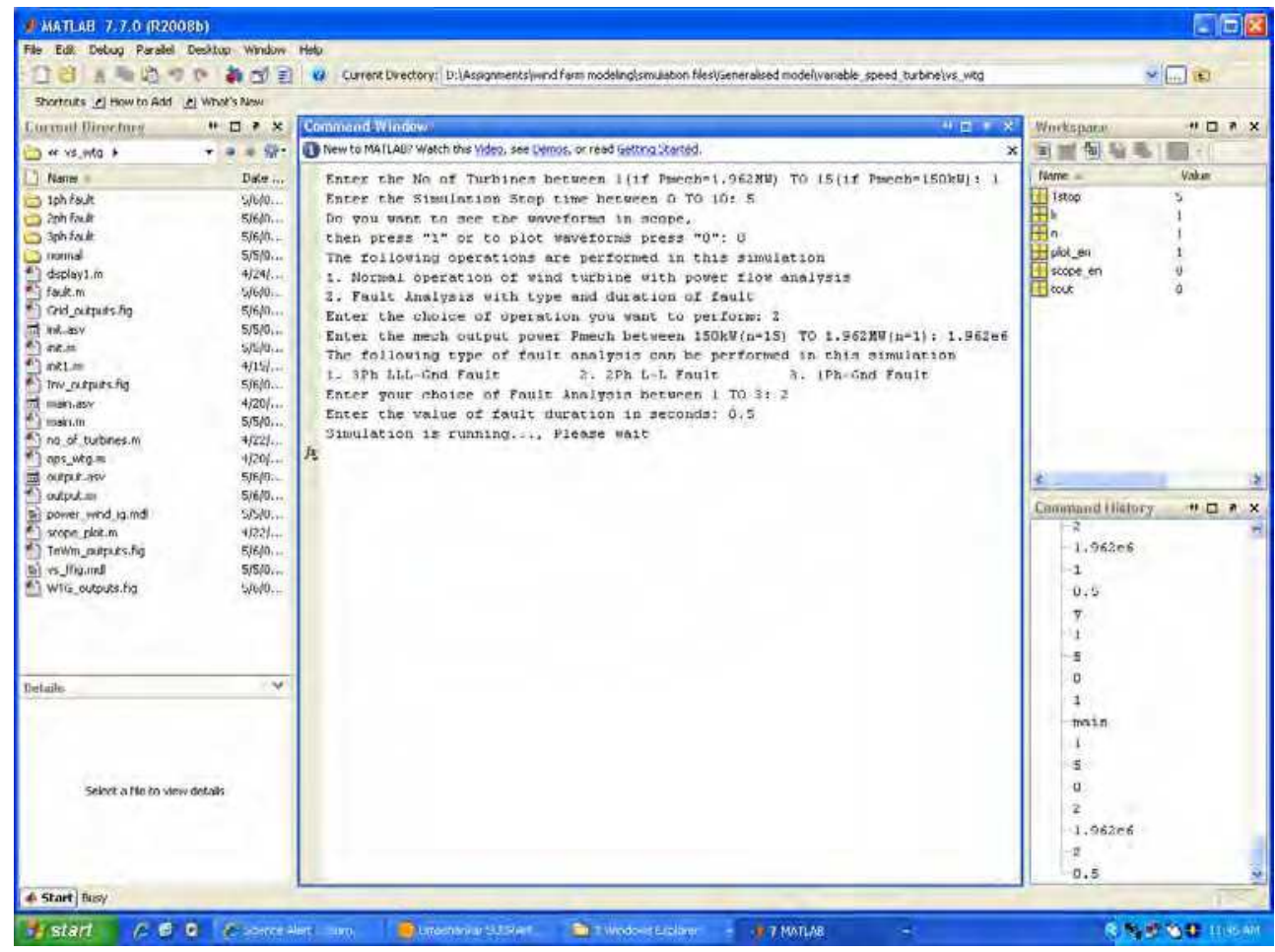

Fig. 23. Matlab command window as user interface, 2 phase grid fault 

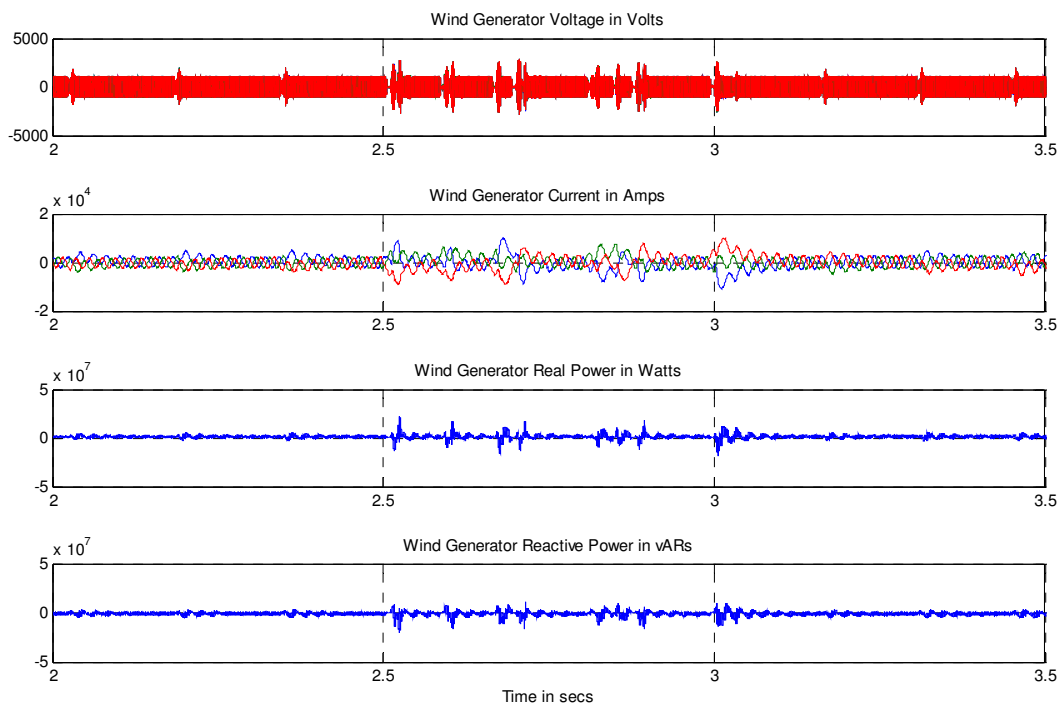

Fig. 24. Generator-side electrical outputs, 2phase grid fault
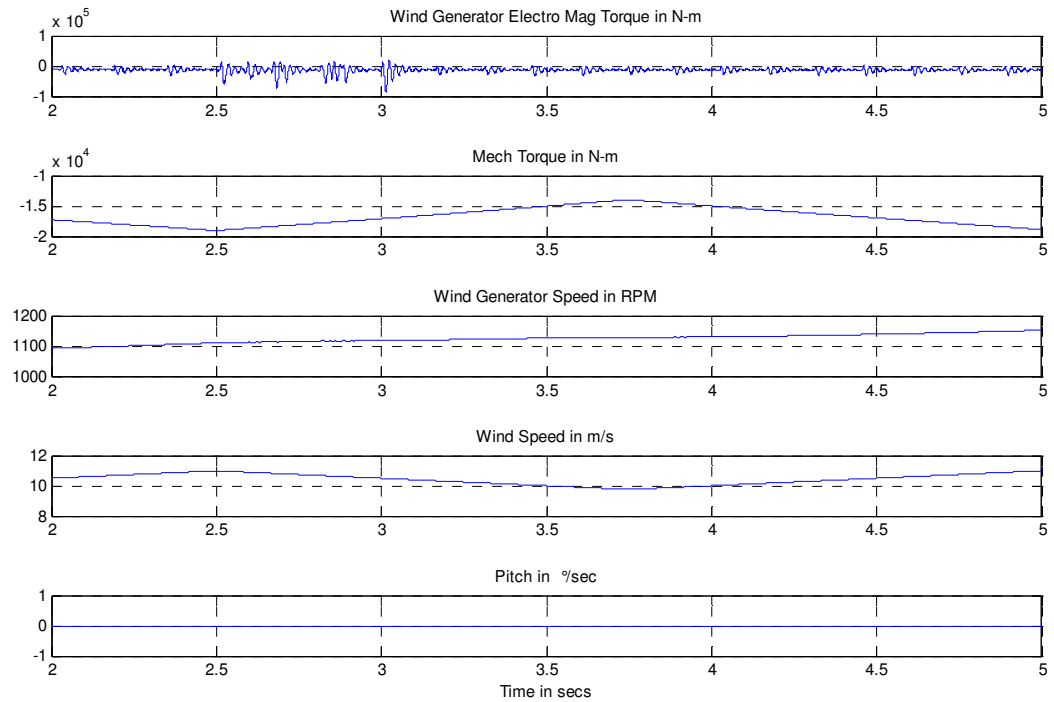

Fig. 25. Generator-side mechanical outputs, 2phase grid fault 

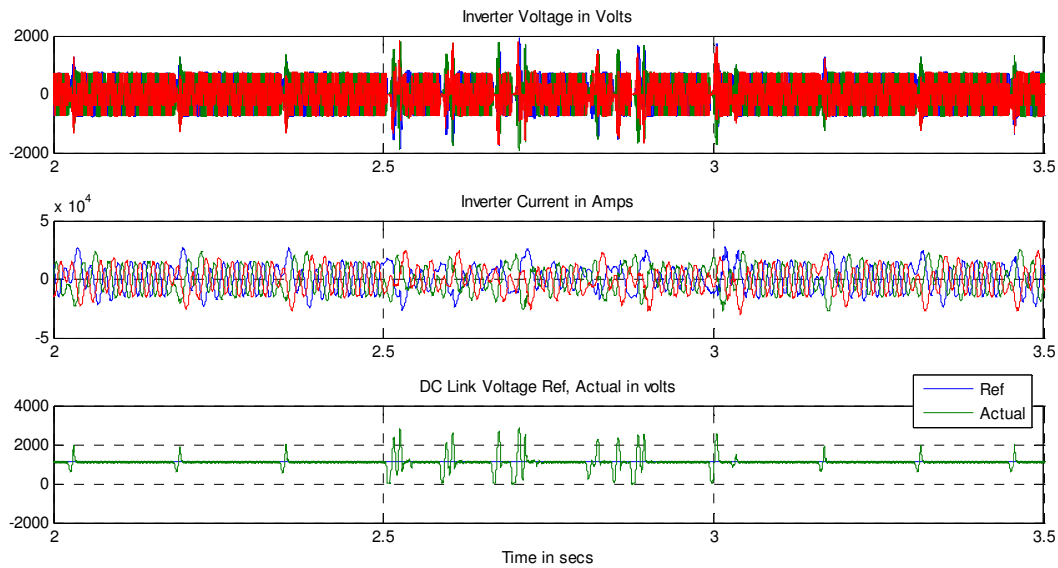

Fig. 26. Inverter Electrical outputs, 2phase grid fault
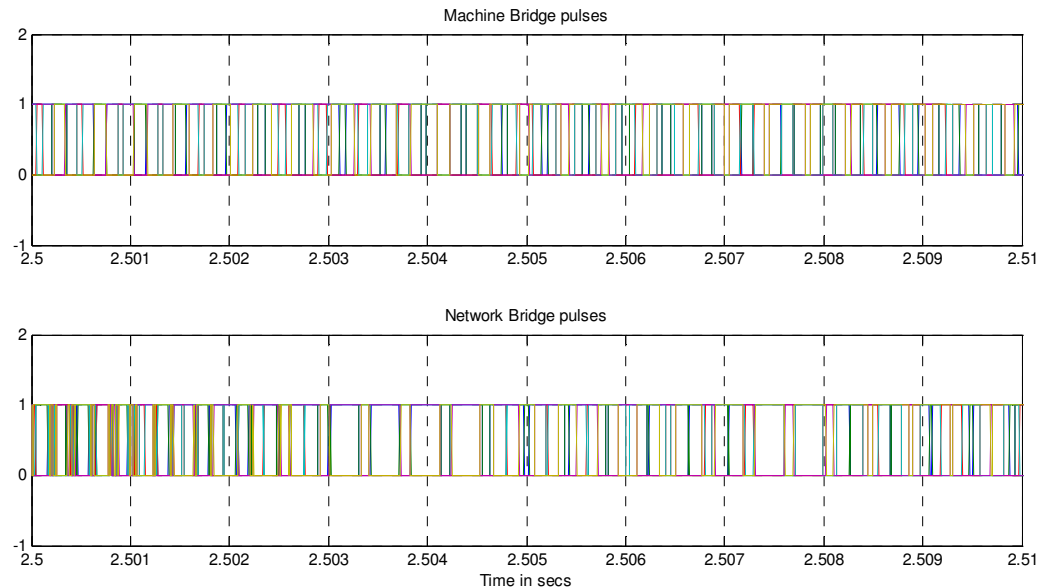

Fig. 27. PWM pulse outputs, 2phase grid fault 

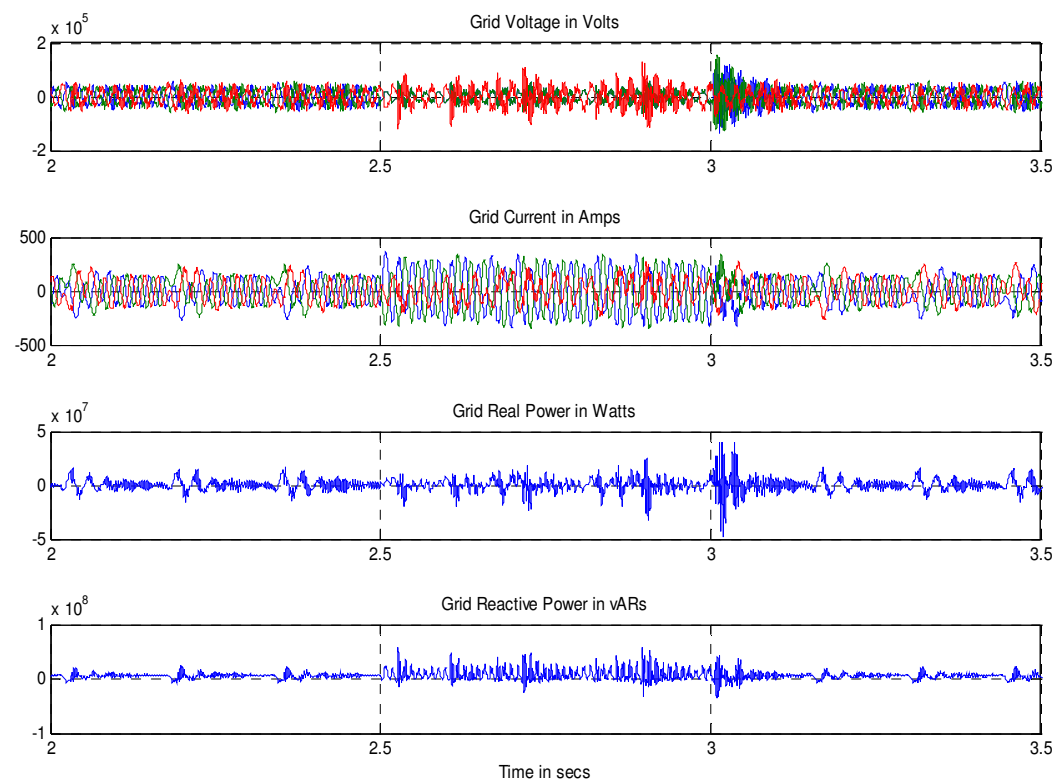

Fig. 28. Grid-side Electrical outputs, 2phase grid fault

\subsection{Two-phase line to line grid fault}

To analyse the model under two-phase line to line grid fault condition, follow the steps in the below snapshot of the matlab command window. After the simulation, command window will prompt for user input to display the results and to save the figures. To start with run the main.m file in command window and follow the steps below:

\subsubsection{Comments on the result}

At rated torque and speed, the FFIG delivers the rated power to grid under normal operation. At time $t=2.5 \mathrm{~s}$, two-phase line to line fault is created at the grid side transmission line hence the grid current abruptly increased. The generator speed will increase above rated speed. Also the actual dc voltage maintained as that of reference.

It is evident from the fig.25. that there is a no mechanical torque reversal during the grid fault but the torque tends to reduce and the oscillations in all the waveforms during grid fault are not severe. Also the shaft between generator and wind turbine will ring at its natural frequency.

At time $t=3$ s fault is cleared and all the quantities will slowly come to its previous condition of normal operation. Implementation of GFRT will rectify this issue and stabilize the electrical parameters during fault and after fault removal. 


\section{Conclusion and future work}

The matlab model created for fully-fed induction generator based wind farm provides good performance under normal and transient (fault) operating conditions. It provides good results for different pwm techniques and fault conditions except the single-phase line to ground fault, which should be verified with help of practical hardware scaled down model or real time data from wind farms.

The present system also consist of machine and network bridge controllers in which the former maintains dc link energy by controlling torque, speed and the later provides controlled real, reactive power to grid.

The performance is achieved by considering assumptions mentioned in section (3), hence this matlab model should be implemented for Grid Fault ride-through and the performance should be evaluated by comparing the results. The system also requires a condition monitoring algorithm to check for faults \& to protect the equipments from malfunctioning or damage and filters to arrest the spikes.

Also this model should be tested at different speeds above \& below rated speed and performance of pitch controller should be verified as an extension to this work.

\section{References}

T. Ackermann (Editor), “Wind Power in Power Systems”, John Wiley \& Sons, Ltd, copyright 2005

V. Akhmatov, H. Knudsen, M. Bruntt, A.H. Nielsen, J.K. Pedersen, N.K. Poulsen, “A dynamic Stability Limit of Grid-Connected Induction Generators", IASTED, Mabella, Spain, September, 2000

M.B. Bana Sharifian, Y. Mohamadrezapour, M. Hosseinpour and S. Torabzade, "Maximum Power Control of Grid Connected Variable Speed Wind System through Back to Back Converters", Journal of Applied Sciences, Vol.8(23), 4416-4421, 2008

Divya, KC and Rao, Nagendra PS,"Study of Dynamic Behavior of Grid Connected Induction Generators", IEEE Power Engineering Society General Meeting, Denver, Colorado, USA, Vol.2, 2200 -2205, 6-10 June, 2004

P. Kundur, "Power System Stability and Control", EPRI, McGraw-Hill, Inc., Copyright 1994

Kim Johnsen, Bo Eliasson, "SIMULINK® Implementation of Wind Farm Model for use in Power System Studies", Nordic Wind Power Conference NWPC'04, Chalmers University of Technology, Göteborg, Sweden, 1-2 March 2004

Øyvind Rogne, Trond Gärtner," Stability for wind farm equipped with induction generators", Nordic PhD course on Wind Power, Smøla, Norway, June 5 - 11, 2005

Paulo Fischer de Toledo, Hailian Xie KTH, Kungl Tekniska Högskolan, "Wind Farm in Weak Grids compensated with STATCOM", Nordic PhD course on Wind Power, Smøla, Norway, June 5 - 11, 2005

J. Soens, J. Driesen, R. Belmans, “Generic Dynamic Wind Farm Model for Power System Simulations," Nordic Wind Power Conference NWPC'04, Chalmers University of Technology, Göteborg, Sweden, 1-2 March 2004 
D. P. Kothari I. J. Nagrath, “Elecrtical Machines”, 3rd Edition, Tata McGraw-Hill, NewDelhi, 2004

D. P. Kothari I. J. Nagrath, "Modern Power System Analysis", 3 ${ }^{\text {rd }}$ Edition, Tata McGrawHill, NewDelhi, 2003 


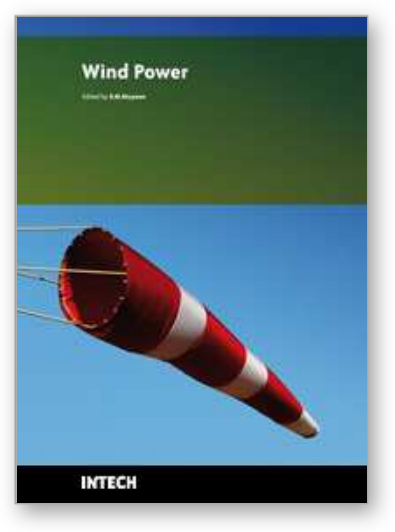

\author{
Wind Power \\ Edited by S M Muyeen
}

ISBN 978-953-7619-81-7

Hard cover, 558 pages

Publisher InTech

Published online 01, June, 2010

Published in print edition June, 2010

This book is the result of inspirations and contributions from many researchers of different fields. A wide verity of research results are merged together to make this book useful for students and researchers who will take contribution for further development of the existing technology. I hope you will enjoy the book, so that my effort to bringing it together for you will be successful. In my capacity, as the Editor of this book, I would like to thanks and appreciate the chapter authors, who ensured the quality of the material as well as submitting their best works. Most of the results presented in to the book have already been published on international journals and appreciated in many international conferences.

\title{
How to reference
}

In order to correctly reference this scholarly work, feel free to copy and paste the following:

Umashankar S., Kothari D. P. and Mangayarkarasi P. (2010). Wind Turbine Modelling of a Fully-Fed Induction Machine, Wind Power, S M Muyeen (Ed.), ISBN: 978-953-7619-81-7, InTech, Available from:

http://www.intechopen.com/books/wind-power/wind-turbine-modelling-of-a-fully-fed-induction-machine

\section{INTECH}

open science | open minds

\section{InTech Europe}

University Campus STeP Ri

Slavka Krautzeka 83/A

51000 Rijeka, Croatia

Phone: +385 (51) 770447

Fax: +385 (51) 686166

www.intechopen.com

\section{InTech China}

Unit 405, Office Block, Hotel Equatorial Shanghai

No.65, Yan An Road (West), Shanghai, 200040, China

中国上海市延安西路65号上海国际贵都大饭店办公楼405单元

Phone: +86-21-62489820

Fax: +86-21-62489821 
(C) 2010 The Author(s). Licensee IntechOpen. This chapter is distributed under the terms of the Creative Commons Attribution-NonCommercialShareAlike-3.0 License, which permits use, distribution and reproduction for non-commercial purposes, provided the original is properly cited and derivative works building on this content are distributed under the same license. 